\title{
Socioeconomic Groups and Cancer Risk at Death in the Swiss Canton of Vaud
}

\author{
FABIO LEVI*, EVA NEGRI $†$ ₹, CARLO LA VECCHIA* $\ddagger$ and VAN CONG TE*
}

\begin{abstract}
Levi F (Vaud Cancer Registry, University Institute of Social and Preventive Medicine, CHUV BH-06, 1011 LaU8anne, Switzerland), Negrl E, Le Vecchia C and Te V C. Socioeconomic groups and cancer risk at death in the Swiss Canton of Vaud. Intermationa/ Joumal of Epidemiology 1988, 17: 711-717.

Date collected by the Cancer Registry of the Canton of Veud, Switzerland, were used to estimate proportional mortality ratios (PMR) and mortality odds ratios (MOR) for various neoplasms according to social class and sector of occupation (agriculture versus others). Mortality ratios were elevated in lower social classes for cancers of the lung (MOR $x 1.18$ for social class IV or V ve I or II) and other sites strictly related to tobacco (mouth or pharynx, oesophagus and larynx; MOR = 1.70), and (though not significantly) for cancers of the stomach (MOR = 1.16) and uterus (MOR = 1.30 for cervix and 1.47 for corpus uteri). Furthermore, there was a strong negative social class gradient for thyrold cancer (a neoplasm with particularly elevated incidence and mortality in Switzeriand), probably attributable to hlgher prevalence of lodine deficiency in lower social clesses (MOR - 3.17). Positive social class gradlents emerged for cancers of the intestines (MOR $=0.77$ for social class IV or V), skln (MOR $=0.74$ ) and prostate (MOR $=0.87$ ). Agricultural workers showed decreased retios for cancers of the lung (MOR $=0.75$ ), cervix uteri (MOR $=0.72$ ) and prostate (MOR $=0.80$ ), and excess mortality from cancers of the upper digestive and respiratory stes (MOR = 1.22), stomach (MOR = 1.18), testis (MOR = 2.05) and lympho-haematopoietic neoplasms, particularty myeloma (MOR = 2.14).
\end{abstract}

Socioeconomic status has long been known to be one of the major determinants of the incidence of various neoplasms. Cancers of the stomach and cervix uteri, for instance, have consistently been found to be higher in lower social classes, whereas cancers of the breast or prostate tend to show positive social class gradients. ${ }^{1-8}$

It is difficult to define and quantify the importance of specific occupational exposures and of various lifestyle correlates of socioeconomic status on subsequent cancer risk. Nonetheless, further reports on this topic are of general interest, since the socioeconomic determinants of cancer risk are known to differ in different countries and time periods. Thus, we present here the results, in terms of proportional mortality ratios and mortality odds ratios, on the relation between social class and mortality from major cancer sites on the basis of incident cases from the Cancer Registry of the Vaud Canton, Switzerland. The dataset was insufficient for

\footnotetext{
- Vaud Cancer Registry, Univervity Institute of Social and Preventive Medicine, CHUV BH-06, 1011 Lausanne, Switzertand

+ Inter-University Consortium of Lombardy for Automatic Data Processing (ClLEA), via R. Sanzio, 20090 Segrate, Milan, Italy. ¥ Mario Negri Institute for Pharmacological Research, via Eritrea 62 , 20157 Milan, Italy.
}

any evaluation of specific occupations, but meaningful analyses could be conducted (and are enclosed in the present report) for the whole of agriculture and forestry workers as compared with all other occupational sectors.

\section{MATERIALS AND METHODS}

The data were derived from the Vaud Cancer Registry datafile, which includes data concerning incident cases of malignant neoplasms in the Canton (whose population in 1980 was about 530,000 inhabitants). ${ }^{9,10}$ Information collected by the register includes general characteristics of the patient (age, sex), site and histological type of the tumour according to the standard International Classification of Diseases (ICD, Ninth Revision) and time of registration. Information on marital status, nationality and occupation is not collected at registration, but is abstracted from death certificates. Occupation is coded according to a detailed three-digit classification provided by the Swiss Federal Office of Statistics, ${ }^{11}$ which is an adaptation of the International Classification of Occupations. ${ }^{12}$

Among the cancer deaths registered between 1977 and 1984 in the population aged 20 to 74 , information on occupation was available for 4461 deceased cases 
(3099 males and 1362 females, 77\% of all deceased cases, $81 \%$ of males and $70 \%$ of females), which constitute the material for these analyses.

Using these occupation codes, it is possible to define socioeconomic groups or social classes comparable to those adopted by the British Registrar General. ${ }^{13}$ Validation of this socioeconomic classification has been considered in a separate study, which showed satisfactory concordance between death certificate and Census data. ${ }^{14}$

In order to obtain meaningful numbers in each category, we grouped the six original social classes into three categories, including respectively the Registrar General's Social classes I and II (professional, managerial and intermediate), social classes III nM or III $M$ (skilled occupations), and social class IV or V (partly skilled and unskilled occupations).

A total of 347 cases could not be classified in terms of social class, and were considered only for analyses related to occupational sector (agriculture versus others).

Observed numbers of deaths for each cancer were tabulated and compared with cause-specific expected numbers based on the proportional cancer mortality experience of the whole dataset, with adjustments for age (in five-year groups) and sex (where appropriate). Cancer proportional mortality ratios (PMRs) were calculated as the ratio of observed to expected deaths for each cancer. ${ }^{15-17}$ Standard errors of the PMRs were based on the Poisson distribution, and their statistical significance was determined by the chi-square test, comparing observed and expected numbers of deaths.

Age- and sex-adjusted mortality odds ratios (MORs) ${ }^{18}$ were computed from $2 \times 2$ tables including deaths for a defined neoplasm versus those from all other neoplasms. Estimates of the MORs were also derived from multiple logistic regression equations, ${ }^{19,20}$ with maximum likelihood fitting ${ }^{21}$ and including simultaneously terms for age, sex, social class, sector of occupation, nationality and marital status. Since ageand sex-adjusted MORs in no case were materially different from the corresponding PMRs, whereas multivariate estimates provided some additional information on the modifying effect of potential confounding factors, only the latter are given in the tables.

\section{RESULTS}

Absolute numbers of cases included in the present analyses for all cancer deaths and each of the 21 cancers or groups of cancers considered are given in Table 1 in separate strata of sex, age, social class and sector of occupation. Overall, there were 3099 males and 1362 females for the agriculture versus other activities analyses, 2848 males and 1266 females for the social class analyses (since social class was undetermined for 347 individuals). By far the commonest cause of cancer death was lung (1010 cases), followed by intestines ( 442 cases), breast ( 280 cases) and prostate (244), whereas a total of 472 cancer deaths were due to various neoplasms of the upper digestive and respiratory tract.

Table 2 gives proportional mortality ratios according to social class in the two sexes separately, while Table 3 reports corresponding estimates for the two sexes combined for non-sexual neoplasms (and for the relevant sex for sexually related ones) both in terms of age- and sex-adjusted proportional mortality ratios and of multivariate mortality odds ratios.

Significant negative social class gradients (ie higher ratios in lower social classes) emerged for cancers of the mouth or pharynx, larynx and oesophagus, lung and thyroid: for these neoplasms, the pattern of trends in ratios was satisfactorily consistent for the two sexes, although the lowest ratio for female lung was observed in the intermediate class. Negative social class gradients (though non-significant) were evident for cancers of the stomach and uterus, too.

Significantly positive social class gradients were apparent for cancers of the intestines, skin (chiefly melanoma) and prostate. Ratios were significantly below unity for lower social classes for non-Hodgkin's lymphomas and significantly above unity in the upper social classes for myeloma, but the trends in ratios for these neoplasms were inconsistent.

Mortality odds ratios, derived from multiple logistic regression equations (including terms for nationality and marital status besides age and sex) give the estimated risk of cancer death for social class III and IV or V compared with social class I or II (reference category). The findings from this analysis are largely consistent with the age- and sex-adjusted proportional mortality ratios although, on account of the large standard errors of the estimate from the model, the tests for linear trend were significant only for cancers of the mouth or pharynx, larynx or oesophagus, lung and thyroid (elevated ratios in lower social classes), and for intestines (lower ratios for lower social classes).

Corresponding analyses (PMRs for males and females, PMRs and MORs for both sexes combined) for agriculture versus other occupations are reported in Table 4. Farmers and other workers in agriculture showed significant excess proportionate mortality for neoplasms of the upper digestive and respiratory tract, gallbladder and bile ducts, testis, myeloma and leukaemias, and significantly decreased ratios for lung, 
TABLE 1 Distribution of cancer deaths from the registry of the Swiss canton of Vaud according to type of cancer and selected variables.

\begin{tabular}{|c|c|c|c|c|c|c|c|c|c|c|}
\hline \multirow[b]{3}{*}{ Type of cancer } & \multicolumn{10}{|c|}{ Number of registered deaths sccording to } \\
\hline & \multicolumn{2}{|c|}{ Sex } & \multicolumn{3}{|c|}{ Age } & \multicolumn{3}{|c|}{ Social cless } & \multicolumn{2}{|c|}{$\begin{array}{l}\text { Sector of } \\
\text { occupstion }\end{array}$} \\
\hline & $\mathbf{M}$ & $\mathbf{F}$ & $<55$ & $55-64$ & 65-74 & $\begin{array}{c}\text { I or II } \\
\text { (Highest) }\end{array}$ & III & IV or $\mathrm{V}$ & $\begin{array}{l}\text { Agri- } \\
\text { culture }\end{array}$ & Other \\
\hline \multicolumn{11}{|l|}{$\begin{array}{l}\text { Mouth or pharynx, } \\
\text { oesophagus and }\end{array}$} \\
\hline larynx & 409 & 63 & 124 & 184 & 164 & 101 & 199 & 131 & 60 & 412 \\
\hline Stomach & 159 & 36 & 32 & 62 & 101 & 57 & 72 & 49 & 25 & 170 \\
\hline \multicolumn{11}{|l|}{ Intertines (chieffy } \\
\hline colon and rectum) & 283 & 159 & 62 & 124 & 256 & 161 & 159 & 88 & 49 & 393 \\
\hline Liver & 82 & 18 & 11 & 36 & 53 & 31 & 37 & 24 & 11 & 89 \\
\hline Gallbladder & 25 & 39 & 9 & 23 & 32 & 17 & 25 & 12 & 12 & 52 \\
\hline Pancreas & 113 & 71 & 22 & 67 & 95 & 62 & 63 & 44 & 20 & 164 \\
\hline Lung & 907 & 103 & 165 & 384 & 461 & 302 & 386 & 261 & 96 & 914 \\
\hline \multicolumn{11}{|l|}{ Skin } \\
\hline (chieffy melanoma) & 180 & 50 & 33 & 45 & 152 & 88 & 75 & 46 & 28 & 202. \\
\hline Brenst & 5 & 275 & 101 & 89 & 90 & 92 & 128 & 39 & 23 & 257 \\
\hline Cervix uteri & - & 62 & 20 & 25 & 17 & 19 & 26 & 13 & 4 & 58 \\
\hline Corpus uteri & - & 45 & 7 & 16 & 22 & 14 & 19 & 11 & 3 & 42 \\
\hline Ovary & - & 101 & 32 & 30 & 39 & 31 & 45 & 17 & 9 & 92 \\
\hline Prostate & 244 & - & 52 & 45 & 194 & 89 & 79 & 55 & 26 & 218 \\
\hline Testis & 19 & - & 16 & 1 & 2 & 5 & 8 & 5 & 4 & 15 \\
\hline Bladder & 147 & 27 & 23 & 5 & 99 & 48 & 73 & 39 & 18 & 156 \\
\hline Kidney & 65 & 33 & 14 & 32 & 52 & 35 & 38 & 18 & 9 & 89 \\
\hline \multicolumn{11}{|l|}{ Brain and } \\
\hline nervous syztem & 75 & 37 & 47 & 31 & 34 & 41 & 41 & 22 & 10 & 102 \\
\hline Thyroid & 11 & 9 & 6 & 6 & 8 & 3 & 9 & 7 & 2 & 18 \\
\hline \multicolumn{11}{|l|}{ Non-Hodgkin's } \\
\hline lymphomas & 77 & 46 & 25 & 43 & 55 & 42 & 51 & 20 & 14 & 109 \\
\hline Myeloma & 35 & 18 & 5 & 19 & 29 & 22 & 10 & 10 & 11 & 42 \\
\hline Leukeemias & 73 & 47 & 31 & 31 & 58 & 35 & 49 & 22 & 19 & 101 \\
\hline Total, all cancer deaths" & 3099 & 1362 & 866 & 1445 & 2150 & 1403 & 1713 & 998 & 481 & 3980 \\
\hline
\end{tabular}

-Including others and undefined

cervix uteri and prostate. Stomach cancer and nonHodgkin's disease were above unity and corpus uteri neoplasms rates below unity in subjects working in agriculture, but these differences were not significant. Likewise, no appreciable difference was observed for other digestive sites, breast, ovary, urinary sites, brain and thyroid.

For the comparisons of agriculture versus other occupations, too, the findings for multiple logistic regression MORs were largely consistent with age- and sex-adjusted PMRs. Significantly elevated MORs for agricultural workers emerged for gallbladder, leukaemias and multiple myeloma, whereas the estimate was significantly below unity for lung cancer.

Finally, we repeated the same analyses for PMR and MOR computation after exclusion of lung cancer, since this neoplasm represented a large proportion of the comparison group and has a major recognized risk factor in smoking. ${ }^{17}$ There were minor changes in the sense of increasing (or reducing) differences between social classes or occupational categories, but in no case were the estimated ratios materially modified. Thus, only estimates based on comparison with all (other) neoplasms were presented.

\section{DISCUSSION}

There are a number of problems in the interpretation of the analyses presented, chiefly due to the relatively small absolute numbers of cases with the consequent limited power to detect significant associations, and to the absence of reliable estimates of the population at risk in various occupational groups. Consequently, we had to rely on estimtes of risk based on cancer PMRs and MORs. In general, the two methods provided consistent estimates, minor differences being restricted to a systematic tendency to underestimate 
TABLE 2 Proportional morality ratiost for selected cancer sites according to social class in the two sexes. Vaud, Swizzeriand, $1977-84$.

\begin{tabular}{|c|c|c|c|c|c|c|}
\hline \multirow[b]{3}{*}{ Type of Cancer } & \multicolumn{6}{|c|}{ Proportional mortality ratios in: } \\
\hline & \multicolumn{3}{|c|}{ Males, social class } & \multicolumn{3}{|c|}{ Females, social class } \\
\hline & $\begin{array}{c}\text { I or II } \\
\text { (Highest) }\end{array}$ & III & IV or $\mathrm{V}$ & $\begin{array}{c}\text { l or II } \\
\text { (Highest) }\end{array}$ & III & IV or $\mathrm{V}$ \\
\hline \multicolumn{7}{|l|}{ Mouth or pharynx, } \\
\hline $\begin{array}{l}\text { Stomach } \\
\text { Intestines (chiefly }\end{array}$ & 0.97 & 0.92 & 1.17 & 0.70 & 1.35 & 0.94 \\
\hline colon and rectum) & 1.29 & 0.89 & $0.82^{*}$ & 1.11 & 0.89 & 1.04 \\
\hline Liver & 0.89 & 1.16 & 0.97 & 1.60 & 0.43 & 1.37 \\
\hline \multicolumn{7}{|l|}{ Gallbladder and } \\
\hline biliary tract & 1.29 & 0.74 & 1.06 & 0.69 & 1.37 & 0.90 \\
\hline Pancreas & 1.12 & 0.84 & 1.07 & 1.12 & 0.77 & 1.25 \\
\hline Lung & 0.90 & 1.04 & $1.07^{*}$ & 1.07 & 0.88 & 1.13 \\
\hline Skin (chiefly melanoma) & 1.39 & 0.82 & 0.86 & 1.38 & 0.70 & 0.98 \\
\hline Bladder & 0.84 & 1.26 & 0.90 & 0.70 & 1.09 & 1.39 \\
\hline Kidney & 1.19 & 1.16 & 0.65 & 1.27 & 0.78 & 1.02 \\
\hline Brain and & & & & & & \\
\hline nervous system & 1.44 & 0.75 & 0.82 & 0.91 & 1.24 & 0.89 \\
\hline Thyroid & 0.45 & 0.85 & $2.19^{*}$ & 0.27 & 1.94 & 1.47 \\
\hline Non-Hodgkins lymphomas & 1.39 & 0.94 & 0.69 & 0.81 & 1.45 & 0.67 \\
\hline Myeloma & 2.31 & 0.49 & 0.73 & 1.51 & 0.36 & 1.88 \\
\hline Leukaemias & 0.94 & 1.02 & 1.05 & 0.99 & 1.45 & 0.48 \\
\hline
\end{tabular}

$p<0.05$ (for linear trend).

+ Adjusted for age.

differences between occupational groups by the PMRs, obviously due to the fact that observed deaths from the cause under examination were included in the computation of expected ones (denominators) as well. ${ }^{15-18}$ A further advantage of MOR estimates was given by the applicability of standard methods of adjustment for covariates, ie logistic regression commonly utilized in the analysis of case-control studies. $^{18,19}$

Nonetheless, it should be stressed that these methods are in any case restricted to an estimate of risk of death in relative terms of comparison with deaths from all (other) cancer deaths, and hence they do not give information on the absolute risk of cancer death in a defined socioeconomic occupational group. Moreover, the fact that we utilized cancer deaths only, and not total mortality, further restricts the inference within the distribution of various cancers, preventing us from inferences on differential overall cancer mortality between various occupational groups, even in relative terms. For instance, total cancer mortality is known to be higher for lower social classes in several countries (ref 4 pp. 104-6), but in the present analysis was obviously constrained to unity. On the other hand, this should inherently correct the present analyses from biases due to the 'healthy worker effect', which are known to produce spurious overestimates of the PMRs for cancer when total mortality is used as reference. ${ }^{15,17}$

Bearing these cautions in mind, it is consequent that the present analysis should be considered preliminary work to generate hypotheses to be tested by further research, or to compare and verify mortality patterns previously reported from studies conducted in other countries.

It is thus interesting to find confirmation in the present dataset of lower mortality ratios in higher social classes for cancers of the lung and other sites strictly related to tobacco (mouth or pharynx, oesophagus and larynx). It is also likely that occupational exposures to carcinogens did play some role in determining these social class differences, at least for lung cancer.

Likewise, the negative social class gradients for cancers of the stomach and (cervix) uteri are largely recognized, as well as the positive gradients for intestinal neoplasms and for skin melanoma. ${ }^{1-8}$

More controversial is the evidence for cancer of the prostate, which showed a positive social class gradient in the present dataset, as well as in various Scandinavian countries, ${ }^{7}$ among white Americans from Los Angeles County, ${ }^{22}$ in a case-control study from Italy ${ }^{23}$ and in England and Wales in the earlier decades of the 
TABle 3 Proportional mortality ratios" and mortality adds ratios" "for selected cancer sites according to social dass. Vaud, Switzerland, $1977-84$.

\begin{tabular}{|c|c|c|c|c|c|c|}
\hline \multirow[b]{2}{*}{ Type of cancer } & \multicolumn{3}{|c|}{$\begin{array}{l}\text { Proportional mortality ratio } \\
\text { for social class }\end{array}$} & \multicolumn{3}{|c|}{$\begin{array}{l}\text { Mortality odds ratio } \\
\text { for social class }\end{array}$} \\
\hline & $\begin{array}{c}\text { I or II } \\
\text { (Highest) }\end{array}$ & III & IV or $\mathbf{V}$ & $\begin{array}{c}\text { I or II } \\
\text { (Highest) }\end{array}$ & III & IV or $\mathbf{V}$ \\
\hline \multicolumn{7}{|l|}{ Mouth or pharynx, } \\
\hline ocsophagus and larynx & 0.62 & 1.28 & $1.22+$ & $1 \ddagger$ & 1.70 & $1.70+$ \\
\hline Stomach & 0.91 & 0.99 & 1.13 & $1 \ddagger$ & 1.05 & 1.16 \\
\hline \multicolumn{7}{|l|}{ Intestines (chiefly } \\
\hline colon and rectum) & 1.22 & 0.89 & $0.88 t$ & $1 \ddagger$ & 0.79 & $0.77 t$ \\
\hline Liver & 0.99 & 0.98 & 1.02 & $1 \ddagger$ & 1.03 & 1.06 \\
\hline Gallbladder and biliary tract & 0.89 & 1.11 & 0.98 & $1 \ddagger$ & 1.22 & 1.18 \\
\hline Pancreas & 1.12 & 0.81 & 1.12 & $1 \neq$ & 0.83 & 1.03 \\
\hline Lung & 0.91 & 1.02 & $1.07 \dagger$ & $1 \ddagger$ & 1.11 & $1.18 t$ \\
\hline Skin (chiefly melanoma) & 1.39 & 0.79 & $0.88 \dagger$ & $1 \ddagger$ & 0.71 & 0.74 \\
\hline Breast & 1.01 & 1.11 & 0.80 & $1 \ddagger$ & 1.09 & 0.80 \\
\hline Cervix uteri & 0.96 & 0.89 & 1.27 & $1 \ddagger$ & 1.00 & 1.30 \\
\hline Corpus uteri & 0.90 & 0.88 & 1.44 & $1 \ddagger$ & 0.96 & 1.47 \\
\hline Ovary & 0.96 & 1.13 & 0.98 & $1 \neq$ & 1.05 & 0.99 \\
\hline Prostate & 1.23 & 0.83 & $0.97 \dagger$ & $1 \ddagger$ & 0.77 & 0.87 \\
\hline Testis & 0.86 & 1.06 & 1.15 & $1 \ddagger$ & 1.32 & 1.46 \\
\hline Bladder & 0.82 & 1.23 & 0.95 & $1 \ddagger$ & 1.31 & 1.13 \\
\hline Kidney & 1.22 & 1.00 & 0.74 & $1 \ddagger$ & 0.91 & 0.73 \\
\hline \multicolumn{7}{|l|}{ Brain and } \\
\hline nervous system & 1.23 & 0.92 & 0.84 & $1 \ddagger$ & 0.81 & 0.78 \\
\hline Thyroid & 0.37 & 1.23 & $1.92+$ & $1 \ddagger$ & 2.19 & $3.17 t$ \\
\hline Non-Hodgkin's lymphomas & 1.14 & 1.13 & 0.69 & $1 \ddagger$ & 0.96 & 0.67 \\
\hline Myeloma & 2.02 & 0.44 & 0.96 & $1 \ddagger$ & 0.36 & 0.64 \\
\hline Leukaemias & 0.96 & 1.19 & 0.86 & $1 \ddagger$ & 1.11 & 0.91 \\
\hline
\end{tabular}

- Adjusted for age and sex.

** Estimates from multiple logistic models including terms for age, sex, nationality and marital status.

$+p<0.05$ (for linear trend).

¥ Reference category.

6 Only cases among women included.

current century, ${ }^{4}$ but not in more recent British data ${ }^{4}$ and on other American studies. ${ }^{6.24}$

A finding deserving consideration in the present study (in spite of the rarity of the disease) is the strong negative social class gradient for thyroid cancer ratios, on account of the exceedingly high rates for this neoplasm in Switzerland. ${ }^{25}$ Thus, although British, Swedish' or American data ${ }^{26}$ are not entirely consistent with these data (the only negative social class gradient being evident among British married women), ${ }^{4}$ it is conceivable that this apparent discrepancy is due to differences in the causes of the disease in various countries. More specifically, assuming that a considerable proportion of Swiss thyroid cancer deaths were due to iodine deficiency, it is conceivable that the deficit was more prevalent among lower social class individuals.

Among the interesting findings of the analyses of agricultural workers there are the decreased ratios for lung cancer (even more pronounced in females) and of the cervix uteri, which should be considered in relation to known risk factors for these diseases (smoking and sexual habits, respectively). In contrast, agricultural workers showed excess mortality ratios for cancer of the stomach, gallbladder, of the upper digestive and respiratory sites, which are probably explainable in terms of differences in dietary habits, including alcohol.

This study showed reduced ratios for prostate cancer and elevated ones for cancer of the testis in agricultural workers. Although the latter association has already been reported, ${ }^{27}$ the overall evidence concerning the relation between agricultural work and male genital tract neoplasms is as yet largely controversial. ${ }^{7.23 .28-30}$

More consistent data have been accumulated over the last few years on a possible association between lympho-haematopoietic neoplasms and agricultural work, ${ }^{29.31-36}$ which is confirmed in the present dataset. This association, which was previously reported from several ${ }^{728.37}$ (but not all) other studies has been tentatively explained in terms of the exposure to viruses or 
TABle 4 Proportional mortality ratios (PMR)* and mortaliny adds ratios (MOR)** for selected cancer sites among individuals accupied in agriculure. Vaud, Switzerland, $1977-84$.

\begin{tabular}{|c|c|c|c|c|}
\hline \multirow[b]{2}{*}{ Type of cancer } & \multirow{2}{*}{$\frac{\text { Males }}{\text { PMR }}$} & \multirow{2}{*}{ Females } & \multicolumn{2}{|c|}{ Total } \\
\hline & & & PMR & MOR \\
\hline $\begin{array}{l}\text { Mouth or pharynx, } \\
\text { oesophagus and larynx }\end{array}$ & $1.26 t$ & 1.18 & $1.25+$ & 1.22 \\
\hline Stomech & 1.09 & $1.65 t$ & 1.17 & 1.18 \\
\hline Intestines (chiefly colon and rectum) & 1.09 & 0.87 & 1.03 & 1.01 \\
\hline Liver & 0.78 & $2.09+$ & 0.94 & 1.05 \\
\hline Gallbladder and biliary tract & $1.90+$ & $2.35+$ & $2.14 \dagger$ & $2.08 t$ \\
\hline Pancreas & 1.07 & 0.93 & 1.03 & 1.11 \\
\hline Lung & $0.85 t$ & $0.94 t$ & $0.82 t$ & $0.75 t$ \\
\hline Skin (chiefly melanoma) & 1.08 & 0.83 & 1.04 & 1.05 \\
\hline Breast & - & 0.99 & - & $0.95 \ddagger$ \\
\hline Cervix uteri & - & $0.77 t$ & - & 0.72 \\
\hline Corpus uteri & - & 0.75 & 一 & 0.75 \\
\hline Ovary & 一 & 1.04 & - & 1.11 \\
\hline Prostate & $0.79+$ & - & 一. & 0.80 \\
\hline Testis & $1.83+$ & - & 一 & 2.05 \\
\hline Bladder & 0.83 & 1.33 & 0.88 & 0.89 \\
\hline Kidney & $0.49+$ & 1.84 & 0.83 & 0.83 \\
\hline Brain and nervous system & 1.21 & - & 0.88 & 0.82 \\
\hline Thyroid & 0.90 & 1.25 & 1.05 & 1.08 \\
\hline Non-Hodgkin's lymphomes & $1.33+$ & 0.73 & 1.13 & 1.14 \\
\hline Myeloma & $1.50+$ & $3.99+$ & $2.10+$ & $2.14 t$ \\
\hline Leukaemias & 1.46 & 1.69 & $1.54 f$ & $1.52 \dagger$ \\
\hline
\end{tabular}

- Adjusted for age and sex (when appropriate).

** Estimates from multiple logistic models mcluding terms for age, sex, nationality and marital status.

$+p<0.05$.

$\ddagger$ Only cases among women included.

chemicals (herbicides) 38 of agricultural workers, although no clear knowledge of the causes of these neoplasms is at present available.

\section{REFERENCES}

' Doll R, Peto R. The causes of cancer. Quantitutive estimates of avoidable risks of cancer in the United States today. JNCI 1981; 66: 1191-1308.

2 Nayha S. Social group and mortality in Finland. Brit J Prev Soc Med 1977; 31: $231-7$.

3 Office of Population Censuses and Surveyn. Occupational mortality. London, Her Majesty's Stationery Office, 1978.

4 Logan W P D. Cancer mortality by occupation and sacial class 18511971. Her Majesty's Stationery Office, London/International Agency for Research on Cancer, Lyon, 1982 (IARC Scient. Publ. No. 36-Studies on Medical and Population Subjects No. 44).

S Fox A J, Adelstein A M. Occapational mortality: work or way of life? J Epidemiol Comm Health 1978; 32: 73-8.

- Blair A, Walrath J, Rogot E. Mortality patterns among U.S. veterans by occupation. 1. Cancer. JNCI 1985; 75: 1039-47.

7 Vigero D, Persson G. Occurrence of cancer in socioeconomic groups in Sweden. An analysis based on the Swedish Cancer Environment Registry. Scand J Soc Med 1986; 14: 151-60.

- Pearce N E, Howard J K. Occupation, wocial dass and male cancer mortality in New Zealand, 1974-78. Int J Epidemiol 1986; 15: 456-62.

'Levi F. Vaud Cancer Registry astistica 1975-1977. In: Cancer Inci- dence in Five Cantinents. Vol. IV, Lyon Intemationaal Agency for Research on Cancer, IARC Scient Publ No. 42, 1982, pp. 546-9.

${ }^{10}$ Levi F. Le cancer dars la population vaudoise. Incidence et mortalite. 1979-1983. Lausanne, Registre Vaudois des TumeursInstitut Universitajre de Médecine Sociale et Préventive, $1985,75 \mathrm{p}$.

"Klassifikation der Berufe fiur die Schlasselung der Statistikkaten der Bevolkerungsbewegung. Bern, Eidg. Statistisches Amt, 1979.

12 International Labour Office. International Standard Classification of Occupations. Geneva, ILO, 1968.

13 Leete R, Fox A J. Registrar General's Social Classes: origins and uses. Population Trends 1977; 8: 1-7.

14 Beer V, Greusing T, Minder C. Berufbezogene sozio-oronomische Gruppen for die Schweiz: cozialwissenschaftliche Grundlagen und Unternuchungen zur Validitat. Soz Proeventivmed 1986; 6: $274-80$.

is Walter S D. Cause-deleted proportional morality analysis and the healthy worker effect. Star Med 1986; 5: 61-71.

16 Decount P, Thomas T L, Pickle L W, Comparison of the proportionate mortality ratio and standardized mortality ratio risk measures. Am J Epidemiol 1980; 111: 263-9.

17 Puntoni R. Ulteriori analisi dei dati di mortalita. In: Atri preliminari del terzo Canvegno Naxionale sugli Studi di Mortalits. Firenze, October 22-24, 1986. Firenze, Lega Italiana per la Lotts contro i Tumori, 1986, pp. 45-54.

4 Miettinen O, Wang J D. An alternative to the proportionate mortality ratio. Am J Epidemiol 1981; 114: 144-8.

* Butler W J, Park R M. Use of logistic regression model for the 
analysis of proportionate mortality data. Am $J$ Epidemiol 1987; 125: 515-23.

20 Robins J M, Blevins D. Aralyzis of proportionate mortality dato using logistic regession madels. Am J Epidemial 1987; 125: 524-35.

${ }^{21}$ Baker R J, Nelder J A. The GLIM System. Retease 3. Oxford, Numerical Algorithms Group, 1978.

2 Ross R K, MCCurtis J W, Henderson B E, Menck H R, Mack T M, Martin S P. Descriptive epidemiology of testicular and prostatic concer in Los Angeles. Br J Cancer 1979; 39: 284-92, 1979.

22 Talamini R, La Veochis C, Decarli A, Negri E, Franceschi S. Nutrition, socinl factors and prostatic cancer in a Northern Italien population. Br J Cancer 1986; 53: 817-21.

${ }^{\star}$ Emster V L, Selvin S, Secks S T, Austin D F, Brown S M, Winkelstein W. Prostate cancer: mortality and incidence rates by race and social class. Am J Epidemiol 1978; 107: 311-20.

Devi F, La Vecchis C, Decarti A, Randriamiharisoa A. Age, birth cohort and period of death effects in Swise cancer mortality, 1951-1984. Int J Cancer 1987; 40: 439-49.

\ McTiernan A M, Weiss N S, Daling J R. Incidence of thyroid cancer in women in relation to reproductive and hormonal factors. Am J Epidemiol 1984; 120: 423-35.

27 Mills $P$ K, Newrell G R, Johnson D E. Testicular cancer associnted with employment in agriculture and oil and natural gas extraction. Lancer 1984; 1: 207-10.

2 Wiklund $K$, Holm L E. Trends in cancer risk among Swedish agricultural workers. JNCI 1986; 77: 657-64.

- Detzell E, Grufferman S. Mortality among white and nonwhite farmers in North Carolina, 1976-1978. Am J Epidemiol 1985; 121: $391-402$.

W Wiklund K. Swedish agricultural workers. A group with a decressed risk of cancer. Cancer 1983; 51: 566-8.

11 Milham S. Leukemia and multiple myeloma in farmers. Am J Epidemiol 1971; 94: 307-10.

Blair A, Thomes T L. Leukemia among Nebraska farmers; a death certificate study. Am J Epidemiol 1979; 110: 264-73.

${ }^{1}$ Blair A, Fraumeni J F, Mason T J. Geographic patterns of leukemia in the United States. J Chron Dis 1980; 33: 251-60.

${ }^{3}$ Burmeister $L F$, Van Lier $S F$, lsacson $P$. Leukemis and farm practices in Iowa. Am J Epiodemiol 1982; 115: 720-8.

$\checkmark$ Pearce N E, Sheppard R A, Howard J K, Fraser J, Lilley B M. Leuknemis among New Zealand agricultural workers. A Cancer Registry based study. Am J Epidemiol 1986; 124: $402-9$.

* Pearce N E, Sheppard R A, Smith A H, Teague C A. NonHodgkin's lymphoma and farming: an expanded case-control study. Int J Cancer 1987; 39: 155-61.

${ }^{7}$ Linos A, Kyle R A, O'Fallon W M, Kuriend L T. A case-control study of occupational exposures and leuknemia. Int J Epidemiol 1980; 9: 131-5.

* Hoar S K, Blair A, Hoimes FF, Boyren C D, Robel R J, Hoover R, Fraumeni J F. Agricultural herbicide use and risk of lymphoms and soft tistue sarcoms. JAMA 1986; 256: 1141-7.

(Revised version received October 1987) 